\title{
A randomised controlled trial of the impact of structured written and verbal advice by community pharmacists on improving hypertension education and control in patients with high blood pressure
}

\author{
Ejaz Cheema ${ }^{1}$ (D) Paul Sutcliffe ${ }^{1} \cdot$ Martin O. Weickert ${ }^{1,2,3} \cdot$ Donald R. J. Singer $^{4}$
}

Received: 12 April 2018 / Accepted: 6 July 2018 / Published online: 18 July 2018

(C) The Author(s) 2018

\begin{abstract}
Purpose This study was aimed to determine whether structured written and verbal education provided to patients by community pharmacists about high blood pressure (BP) and its treatment would be (a) better retained and (b) be associated with improved BP control as compared to patients receiving verbal advice only.

Methods The study was designed as a randomised controlled trial and was conducted in the West Midlands, UK, between January 2014 and June 2014. The primary outcome measures were differences in systolic and diastolic BP from baseline and retention of information about high BP assessed with a questionnaire at 2-, 4- and 26-week follow-up points.

Results A total of 64 adults were included in the study. At the week 26 follow-up, compared to participants in the control group, there was a significant improvement in the knowledge of intervention participants about the risks associated with high BP $(p<$ $0.001)$ and awareness about potential adverse effects of the new BP medicine $(p<0.001)$. Similarly, there was a greater and more significant reduction in systolic BP in favour of the intervention group $8 \mathrm{mmHg}$ (95\% CI 2.1-13.3 $p=0.009$ ) compared to $6 \mathrm{mmHg}(95 \% \mathrm{CI} 0.6-11.7 p=0.02)$ in the control group at the week 4 follow-up. However, this greater effect of an intervention on BP was not sustained at the 26-week follow-up. For diastolic BP, there was no added effect of the intervention.

Conclusion This randomised controlled trial suggests that although written advice provided by community pharmacists in comparison to verbal advice was more effective in improving knowledge and understanding of patients about hypertension and its treatment, it did not lead to better blood pressure control.
\end{abstract}

Keywords Community pharmacists $\cdot$ Education $\cdot$ Hypertension $\cdot$ Randomised controlled trial

\section{Introduction}

It has been reported that behavioural interventions-patientcentred counselling, self-monitoring of blood pressure (BP) and structured training courses - on BP management lead to

Ejaz Cheema

$1 @$ warwick.ac.uk

1 Warwick Medical School, Gibbet Hill Campus, University of Warwick, Coventry CV4 7AL, UK

2 WISDEM Centre, University Hospitals Coventry and Warwickshire NHS Trust, Coventry, UK

3 Centre of Applied Biological and Exercise Sciences, Faculty of Health and Life Sciences, Coventry University, Coventry, UK

4 Fellowship of Postgraduate Medicine, 12 Chandos street, London, UK better BP control in patients with hypertension as compared to patients receiving ordinary care [1]. Pooled results from this systematic review that included 15 studies involving 4072 patients reported that patient-centred counselling led to a reduction of $11.1 \mathrm{mmHg}$ in systolic and $3.2 \mathrm{mmHg}$ reduction in diastolic BP [1]. The review did not specify if the patientcentred counselling was written or verbal. Similar findings were reported in a cluster randomised controlled study in the USA [2]. Patients receiving multifactorial interventions including written patient education experienced a reduction of $8 \mathrm{mmHg}$ in systolic BP and achieved a better BP control. Lack of adequate knowledge about high BP has been reported as a barrier to medication adherence by hypertensive patients [3].

In the UK, the New Medicines Service (NMS) allows community pharmacists to explain medicine use to patients with long-term medical conditions such as hypertension. Within this scheme, the advice is structured but verbal, with no specific written information provided on drugs or the disease 
being treated. There is limited evidence to suggest that provision of written medical advice to patients about a disease and its treatment is better retained by patients than verbal information [4] and leads to better clinical outcomes [2]. The study aimed to determine whether the structured information provided to patients verbally and in writing by community pharmacists about high BP will be associated with improved BP control and be better retained by patients.

\section{Methods}

This study was a 6-month multicentre randomised controlled trial (RCT) conducted across four community pharmacies in the West Midlands area of the UK between January 2014 and June 2014. The trial was registered on ClinicalTrials.gov (Identifier NCT01939860). Participants in both groups were required to attend four visits in total over a period of 6 months (at week 0, 2, 4 and 26).

\section{Study participants and procedures}

All participants 18 years or over, male or female and had been started on a BP medication were eligible for the study. Eligible participants were identified by a member of the pharmacy team. Exclusion criteria included patients under 18 years and patients not capable of giving written consent.

The questionnaire drawn from a 12-item questionnaire developed by the National Institutes of Health [5] was aimed to explore participants' basic knowledge of BP including awareness about the risks associated with high BP and knowledge about the participants' new BP medicine. Face validity of the questionnaire was undertaken by seeking feedback from a pharmacists advisory group including six pharmacists as well as from an expert hypertension advisory group based in the West Midlands area. Besides, the questionnaire was also piloted on a group of 20 patients that included patients attending the BP Clinic at a large teaching hospital in the West Midlands and patients attending one of the participating pharmacies in Birmingham. Based on the feedback obtained during pilot work, the wording of some of the questions of the questionnaire was edited to make the questions simpler and easier to understand. The final questionnaire had a FleschKincaid reading grade level of 5.8 [6].

Three readings of systolic and diastolic BP were recorded for both intervention and control groups participants during all four visits (weeks 0, 2, 4 and 26). BP was recorded electronically by trained pharmacy staff using a British Hypertension Society (BHS)-approved Omron BP monitor [7]. As per the BHS guidelines, the final two readings of both systolic and diastolic BP were used to calculate the average readings.

\section{Intervention and comparator (usual care)}

Participants in both groups were asked to continue to take their prescribed anti-hypertensive medications during the study. In addition to usual care, participants in the intervention group received individually tailored information sheets containing structured advice on BP and their anti-hypertensive medication that was prepared using National Institute for Health and Care Excellence (NICE) guidance CG 127 [8]. These information sheets were provided by a trained pharmacist during three face to face sessions (week 0, 2 and 4) over a period of 6 months. All participating pharmacists were provided 30-min training by the chief investigator of the study. Besides, training was provided to pharmacy staff on measuring blood pressure. Pharmacists were specifically instructed not to provide any help with answering the questions as the same questionnaire was used during all four visits. However, pharmacists were allowed to assist the participants in understanding the medical terminologies used in the questions when needed. The participants in the control group received a separate information sheet containing information on the NMS in addition to usual care.

\section{Data management and analysis}

The sample size calculation indicated that a sample size of 54 per group completing the study will provide a power of $80 \%$ at the $5 \%$ level in a two-tailed test to detect a reduction of a size equal to 0.6 standard deviations (SD) in systolic and diastolic BP. The primary outcome of the study was to detect the difference in systolic and diastolic BP from baseline. The secondary outcome was the retention of information about BP assessed with a questionnaire at 2, 4 and 26 weeks followup. ANOVA was used to calculate the mean difference in systolic and diastolic BP (in $\mathrm{mmHg}$ ). Cross tabulation was used to analyse the responses to hypertension knowledge questions.

\section{Results}

A total of 64 participants were included in the study (see Fig. 1 for flow of participants through the study). At baseline, no statistically significant differences were found in the demographics of intervention and the control group participants (see Table 1 for participant demographics).

\section{Impact on systolic and diastolic BP}

At the end of week 4 follow-up, there was a greater reduction in systolic BP in favour of the intervention group $8 \mathrm{mmHg}$ (95\% CI 2.1-13.3 $p=0.009$ ) compared to $6 \mathrm{mmHg}$ (95\% CI $0.6-11.7 p=0.02)$ in the control group. However, this greater 
Fig. 1 Flow of participants through the study

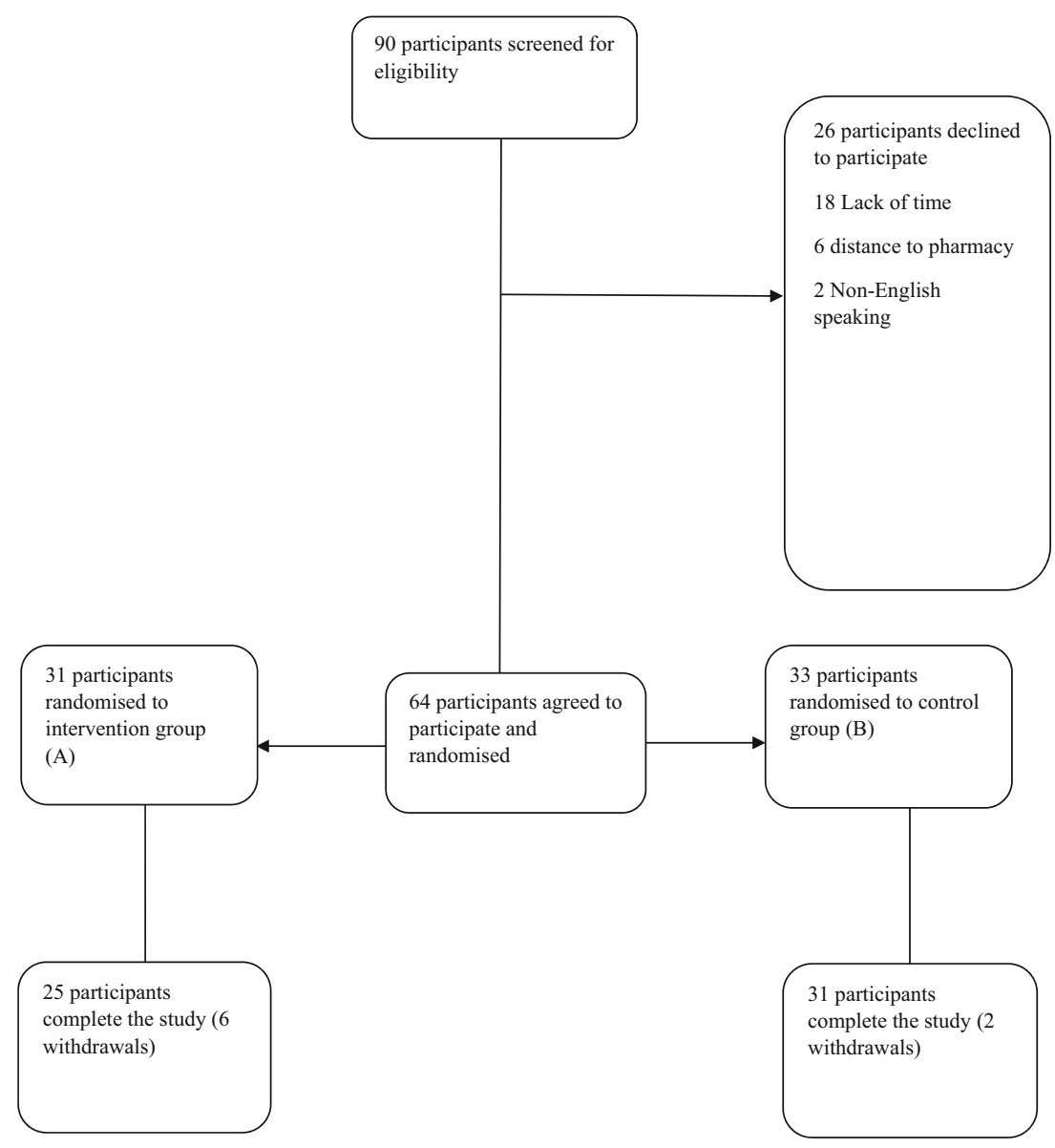

Table 1 Participant demographics at Baseline. BMI— body mass index. All data are given in numbers (percentages) unless otherwise indicated

\begin{tabular}{|c|c|c|}
\hline Variables & Intervention & Control \\
\hline Mean age years (SD) & $64.7(10.5)$ & $60.0(9.3)$ \\
\hline \multicolumn{3}{|l|}{ Gender } \\
\hline Male & $14(45 \%)$ & $18(55 \%)$ \\
\hline Female & $17(55 \%)$ & $15(45 \%)$ \\
\hline \multicolumn{3}{|l|}{ Ethnicity } \\
\hline White Caucasian & $24(78 \%)$ & $25(76 \%)$ \\
\hline South Asian & $5(16 \%)$ & $6(18 \%)$ \\
\hline African Caribbean & $2(6 \%)$ & $2(6 \%)$ \\
\hline Mean BMI kg/m² (SD) & $29.0(5.9)$ & $30.3(5.2)$ \\
\hline Systolic blood pressure mmHg (SD) & $142(17.0)$ & $143(16.9)$ \\
\hline Diastolic blood pressure mmHg (SD) & $79(11.4)$ & $83(12.9)$ \\
\hline Other medical conditions (self-reported) & $6(19 \%)$ & $7(21 \%)$ \\
\hline Diabetes & $1(3 \%)$ & 0 \\
\hline Heart failure & $1(3 \%)$ & $1(3 \%)$ \\
\hline Kidney disease & $1(3 \%)$ & $4(13 \%)$ \\
\hline Heart attack & $1(3 \%)$ & $1(3 \%)$ \\
\hline Stroke & $21(67 \%)$ & $20(60 \%)$ \\
\hline
\end{tabular}

effect of intervention on systolic BP was not sustained at the 26-week follow-up with little difference remaining between the groups, $8 \mathrm{mmHg}(95 \% \mathrm{CI} 2.1-13.3 p=0.01)$ intervention group vs. $7 \mathrm{mmHg}$ (95\% confidence interval $0.6-11.7 p=$ 0.02) control group. For diastolic BP, there was no added effect of the intervention and both groups achieved a similar reduction in diastolic $\mathrm{BP}$ at the 26-week follow-up, $4.5 \mathrm{mmHg}$ (95\% CI 1.2-7.7 $p=0.008$ ) intervention group vs. $5 \mathrm{mmHg}$ (95\% CI 1.3-8.8 $p=0.009)$.

\section{Knowledge about hypertension and its treatment}

With regard to the assessment of knowledge about BP, there was a significant improvement in the knowledge of intervention participants in comparison to participants in the control group at the 26-week follow-up including knowledge about the risks associated with high blood pressure $(p<0.001)$, the role of lifestyle measures in reducing high blood pressure $(p<$ 0.01 ) and awareness about potential adverse effects of the new blood pressure medicine $(p<0.001)$ (see Table 2 for percentages of participants correctly answering each hypertension knowledge question). 
Table 2 Percentages of participants correctly answering each hypertension knowledge question

\begin{tabular}{|c|c|c|c|c|c|c|c|c|}
\hline \multirow[b]{2}{*}{$\begin{array}{l}\text { Knowledge } \\
\text { question }\end{array}$} & \multirow{2}{*}{$\begin{array}{l}\text { Intervention } \\
(n=25) \\
\text { Baseline }\end{array}$} & \multicolumn{4}{|l|}{$\begin{array}{l}\text { Control } \\
(n=31)\end{array}$} & \multicolumn{3}{|c|}{$\begin{array}{l}\text { Difference between groups } \\
\text { expressed by } p \text { value+ }\end{array}$} \\
\hline & & Follow-up & $\begin{array}{l}\text { Difference } \\
\text { within group } \\
p \text { value* }\end{array}$ & Baseline & Follow-up & $\begin{array}{l}\text { Difference } \\
\text { within group } \\
p \text { value* }\end{array}$ & Baseline & Follow-up \\
\hline $\begin{array}{l}\text { Top blood pressure number } \\
\text { should be under } 140 ?\end{array}$ & $16(64 \%)$ & $24(96 \%)$ & $p=0.01$ & $18(58 \%)$ & $23(74 \%)$ & $p=0.25$ & $p=0.65$ & $p=0.02$ \\
\hline $\begin{array}{l}\text { Lower blood number } \\
\text { should be under } 90 ?\end{array}$ & $15(60 \%)$ & $24(96 \%)$ & $p=0.02$ & $21(68 \%)$ & $24(77 \%)$ & $p=0.85$ & $p=0.54$ & $p=0.04$ \\
\hline $\begin{array}{l}\text { Hypertension is a } \\
\text { lifelong disease? }\end{array}$ & $11(44 \%)$ & $25(100 \%)$ & $p<0.001$ & $20(65 \%)$ & $25(84 \%)$ & $p=0.29$ & $p=0.12$ & $p=0.02$ \\
\hline $\begin{array}{l}\text { Hypertension can cause } \\
\text { heart attacks? }\end{array}$ & $11(44 \%)$ & $25(100 \%)$ & $p<0.001$ & $20(65 \%)$ & $25(84 \%)$ & $p=0.51$ & $p=0.99$ & $p=0.19$ \\
\hline $\begin{array}{l}\text { Hypertension can cause } \\
\text { strokes? }\end{array}$ & $21(84 \%)$ & $25(100 \%)$ & $p=0.03$ & $26(84 \%)$ & $29(94 \%)$ & $p=0.09$ & $p=0.47$ & $p=0.36$ \\
\hline $\begin{array}{l}\text { Hypertension can cause } \\
\text { kidney disease? }\end{array}$ & $21(84 \%)$ & $25(100 \%)$ & $p=0.20$ & $21(68 \%)$ & $25(80 \%)$ & $p=0.30$ & $p=0.87$ & $p=0.36$ \\
\hline $\begin{array}{l}\text { Hypertension does not } \\
\text { cause asthma? }\end{array}$ & $14(56 \%)$ & $23(92 \%)$ & $p=0.03$ & $18(58 \%)$ & $22(71 \%)$ & $p=0.20$ & $p=0.68$ & $p=0.12$ \\
\hline $\begin{array}{l}\text { Hypertension does not } \\
\text { cause cancer? }\end{array}$ & $12(48 \%)$ & $19(76 \%)$ & $p=0.02$ & $13(42 \%)$ & $18(58 \%)$ & $p=0.18$ & $p=0.87$ & $p=0.14$ \\
\hline $\begin{array}{l}\text { Losing weight reduces } \\
\text { high blood pressure? }\end{array}$ & $15(60 \%)$ & $23(92 \%)$ & $p=0.005$ & $12(39 \%)$ & $16(52 \%)$ & $p=0.39$ & $p=0.04$ & $p=0.41$ \\
\hline $\begin{array}{l}\text { Cutting salt reduces high } \\
\text { blood pressure? }\end{array}$ & $20(80 \%)$ & $24(96 \%)$ & $p=0.004$ & $26(84 \%)$ & $29(94 \%)$ & $p=0.44$ & $p=0.70$ & $p=0.25$ \\
\hline $\begin{array}{l}\text { Cutting alcohol reduces } \\
\text { high blood pressure? }\end{array}$ & $19(76 \%)$ & $25(100 \%)$ & $p=0.18$ & $28(90 \%)$ & $30(97 \%)$ & $p=0.65$ & $p=0.27$ & $p=0.41$ \\
\hline $\begin{array}{l}\text { Anti-hypertensive should } \\
\text { be taken daily? }\end{array}$ & $19(76 \%)$ & $25(100 \%)$ & $p=0.002$ & $28(90 \%)$ & $30(97 \%)$ & $p=0.79$ & $p=0.04$ & $p=0.19$ \\
\hline $\begin{array}{l}\text { Anti-hypertensive should } \\
\text { be taken long-term? }\end{array}$ & $22(88 \%)$ & $25(100 \%)$ & $p=0.45$ & $28(90 \%)$ & $28(90 \%)$ & $p=0.34$ & $p=0.27$ & $p=0.11$ \\
\hline $\begin{array}{l}\text { Name of your new blood } \\
\text { pressure medicine? }\end{array}$ & $20(80 \%)$ & $25(100 \%)$ & $p=0.01$ & $28(90 \%)$ & $28(90 \%)$ & $p=0.35$ & $p=0.96$ & $p=0.43$ \\
\hline $\begin{array}{l}\text { Dose of your new blood } \\
\text { pressure medicine? }\end{array}$ & $16(64 \%)$ & $20(80 \%)$ & $p=0.08$ & $20(65 \%)$ & $22(71 \%)$ & $p=0.81$ & $p=0.81$ & $p=0.25$ \\
\hline $\begin{array}{l}\text { How your new blood } \\
\text { pressure medicine } \\
\text { works? }\end{array}$ & $17(68 \%)$ & $21(84 \%)$ & $p=0.09$ & $22(71 \%)$ & $22(71 \%)$ & $p=0.03$ & $p=0.07$ & $p=0.01$ \\
\hline $\begin{array}{l}\text { Awareness about } \\
\text { adverse effects? }\end{array}$ & $6(24 \%)$ & $21(84 \%)$ & $p<0.001$ & $7(23 \%)$ & $11(35 \%)$ & $p=0.21$ & $p=0.90$ & $p<0.001$ \\
\hline $\begin{array}{l}\text { Incidence of adverse } \\
\text { effects? }\end{array}$ & $10(40 \%)$ & $5(20 \%)$ & $p=0.12$ & $8(26 \%)$ & $6(19 \%)$ & $p=0.55$ & $p=0.39$ & $p=1.00$ \\
\hline
\end{tabular}

*Chi-square test at $p<0.05 . p$ value* indicates the difference within the study groups and $p$ value+ indicates the difference between the study groups

\section{Discussion}

The findings of this study suggest that although there was a greater reduction in systolic BP in favour of the intervention group compared to control group at the 4-week follow-up, this greater effect of intervention on BP was not sustained at the 26-week follow-up with both groups achieving similar reduction in BP. These findings suggest that verbal advice provided by pharmacists alone was equally effective as the written advice in supporting a reduction in systolic and diastolic BP of hypertensive patients following the introduction of a new BPlowering medicine. However, compared to verbal advice only, provision of structured verbal and written education was associated with an improvement sustained over 6 months in the knowledge of hypertension.

There can be many possible reasons for the nonsustainability of greater BP control initially achieved by intervention participants over the long-term follow-up. It is not completely clear if the intervention participants initially responded better to their new BP treatment than the control participants. Another reason for the loss of their greater BP control could be that perhaps they needed frequent reminders about high BP and its treatment. A recent study that included 1300 adults with high BP compared two intervention groups who received education about high $\mathrm{BP}$ and its treatment through text message reminders and interactive text 
messaging to a control group receiving standard care. The study reported that those who had received text messages had a slightly greater reduction in their BP and were more likely to have achieved a controlled BP [9].

This study has several limitations. Although, the study reported a greater initial reduction in systolic BP of intervention participants compared to control group, such initial better blood pressure control could have been explained by the risk of confounding factors including the type and dose of antihypertensives used, and degree of patient compliance with their medication. Such confounders could have been addressed by appropriate matching of controls. In addition, we were not able to recruit the initially planned number of participants, resulting in reduced power for assessment of the outcome measures. This was primarily due to the withdrawal of two participating pharmacies from the study. Finally, owing to the nature of pharmacists' interventions in this study, participants and the investigators could not be blinded to the study intervention.

The initial reduction in BP by pharmacist-led interventions has important implications for primary and secondary prevention of cardiovascular morbidity and mortality. For example, evidence from a meta-analysis reported that even a $2-\mathrm{mmHg}$ reduction in systolic BP could reduce the risk of stroke by $10 \%$ in the USA [10]. Another analysis suggests that a sustained 2-mmHg reduction in diastolic BP would be expected to result in a $6 \%$ reduction in the risk of coronary heart disease and $15 \%$ decrease in stroke [11]. However, since fewer participants were recruited in the study than required, findings of this study should therefore be interpreted with caution. Future studies with adequate sample size would be required to assess the effectiveness and sustainability of pharmacist-led interventions in the long term in clinical practice.

\section{Conclusion}

This randomised controlled trial suggests that although written advice provided by community pharmacists in comparison to verbal advice was more effective in improving knowledge and understanding of patients about hypertension and its treatment, it did not lead to better blood pressure control.

Acknowledgments We would like to thank Dr. Magdy Sakr, John Goes and Jayne Hoxey for their support in data collection.

Contributions of authors statement Prof. Singer conceived the research idea and designed the study, Dr. Cheema performed research and analysed the data, Prof. Weickert together with Dr. Sutcliffe contributed in manuscript preparation.

\section{Compliance with ethical standards}

Conflict of interest The authors declare that they have no conflict of interest.
Informed consent Informed consent to participate was obtained from all participants.

Ethical approval All procedures performed in this study were in accordance with the ethical standards of national research ethics committee and with the 1964 Helsinki declaration and its later amendments or comparable ethical standards.

Open Access This article is distributed under the terms of the Creative Commons Attribution 4.0 International License (http:// creativecommons.org/licenses/by/4.0/), which permits unrestricted use, distribution, and reproduction in any medium, provided you give appropriate credit to the original author(s) and the source, provide a link to the Creative Commons license, and indicate if changes were made.

\section{References}

1. Boulware LE, Daumit GL, Frick KD, Minkovitz CS, Lawrence RS, Powe NR (2001) An evidence-based review of patient-centered behavioral interventions for hypertension. Am J Prev Med 21: 221-232

2. Roumie CL, Elasy TA, Greevy R, Griffin MR, Liu X, Stone WJ, Wallston KA, Dittus RS, Alvarez V, Cobb J, Speroff T (2006) Improving blood pressure control through provider education, provider alerts, and patient education: a cluster randomized trial. Ann Intern Med 145:165-175

3. Osterberg L, Blaschke T (2005) Adherence to medication. N Engl J Med 353:487-497

4. Victoria G (1981) Written advice: compliance and recall. J R Coll Gen Pract 31:553-556

5. Martins D, Gor D, Teklehaimanot S, Norris K (2001) High blood pressure knowledge in an urban African-American community. Ethn Dis 11:90-96

6. Flesch R (1948) A new readability yardstick. J Appl Psychol 32: 221-233

7. El Assaad MA, Topouchian JA, Asmar RG (2003) Evaluation of two devices for self-measurement of blood pressure according to the international protocol: the Omron M5-I and the Omron 705IT. Blood Press Monit 8:127-133

8. National institute for health and clinical excellence (NICE) (2011) Hypertension: clinical management of primary hypertension in adults in primary care. NICE Clinical Guideline no 127 . NICE, London. www.nice.org.uk/nicemedia/live/13561/56008/56008. pdf. Accessed 19 Sept 2014

9. Bobrow K, Farmer AJ, Springer D, Shanyinde M, Yu LM, Brennan T, Rayner B, Namane M, Steyn K, Tarassenko L, Levitt N (2016) Mobile phone text messages to support treatment adherence in adults with high blood pressure (SMS-text adherence support [StAR]): a single-blind, randomized trial. Circulation 133:592-600

10. Lewington S, Clarke R, Qizilbash N, Peto R, Collins R, Collaboration PS (2002) Age-specific relevance of usual blood pressure to vascular mortality: a meta-analysis of individual data for one million adults in 61 prospective studies. Lancet 360:19031913

11. Cook NR, Cohen J, Hebert PR, Taylor JO, Hennekens CH (1995) Implications of small reductions in diastolic blood pressure for primary prevention. Arch Intern Med 155:701-709 